(c) 2009 Elsevier Ltd All rights reserved.

\title{
Optimisation of liquor yield during the hydraulic pressing of sardine (Sardina pilchardus) discards
}

\author{
Raúl Pérez-Gálvez ${ }^{\mathrm{a}, ~}{ }^{\star}$, Christine Chopin $^{\mathrm{a}}$, Max Mastail $^{\mathrm{a}}$, Jean-Yves Ragon $^{\mathrm{a}}$, Antonio Guadix ${ }^{\mathrm{b}}$ \\ and Jean-Pascal Bergéa
}

\author{
a Département Sciences et Techniques Alimentaires Marines, IFREMER Centre de Nantes, BP 21105, 44311 \\ Nantes Cedex 03, France \\ ${ }^{\mathrm{b}}$ Departamento de Ingeniería Química, Universidad de Granada, 18071 Granada, Spain \\ *: Corresponding author : Raúl Pérez-Gálvez, Tel.: +33 240374079; fax: +33 240374071, email \\ address : rperezga@ifremer.fr
}

\begin{abstract}
:
Fresh sardine (employed as discard model species) was pressed with a hydraulic press in order to obtain a partially dewatered cake (whose volume represents between $55 \%$ and $60 \%$ of the initial volume of raw material) and a 3-phase press liquor comprising an aqueous fraction, an oil fraction and a variable amount of suspended solids. Pressing conditions, such as final pressure to which the sardine was subjected, compression speed, number of pressing stages and time of relaxation between two consecutive pressing stages, were optimised by means of a statistically designed experiment. The goal of the optimisation problem was to achieve maximal yield of press liquor with a minimum load of suspended solids. The suspended solid content in the press liquor must be kept to a minimum in order to facilitate any further treatment by operations such as membrane filtration. The conflict between these two objectives suggested employing a multiobjective optimisation technique. A Pareto Front was generated in order to find a set of solutions which satisfied both objectives to an adequate degree.
\end{abstract}

Keywords: Sardine; Fish discards; Hydraulic pressing; Response surface methodology; Multiobjective optimisation 


\section{Introduction}

A direct consequence of traditional fishing practices is the considerable quantities of wastes and by-products which are generated. They represent an economical and environmental problem since the major wastes are often underutilized creating disposal problems and environmental concerns (Folador et al., 2006). With the aim of classifying and quantifying these by-products, three main groups are considered: discards, wastage on board (wastes generated by fish processing inside the vessels) and byproducts and wastage on shore, due to fish processing and trade industry (Blanco et al., 2007). Discards or discarded catch is that portion of the total organic material of animal origin in the catch comprising small-sized and non-targeted species with low commercial value and traditionally dumped at sea. Quantification of discards and knowledge of trends in discarding practices are of value in the design of fisheries management regimes and initiatives to promote responsible fishing operations and catch utilization. FAO is mandated to report periodically to the United Nations on the implementation of the resolutions and to promote efforts to reduce or minimize discards, drawing the attention to wastage of fishery resources. The FAO assessment (FAO, 2004) compiles information on catches and discards from the world's fisheries during the period from 1992 to 2001. This study assumes that discards are a function of a fishery, defined in terms of an area, fishing gear and target species, and has estimated global discards to be 7.3 million tones, with a global discard rate (quantity of discards as a percentage of the total catch) of $8 \%$. International instruments, including UN resolutions, the Kyoto Declaration and the European Code of sustainable and responsible fisheries practices (EU, 2004) have highlighted the need to reduce, or minimise discards.

Regarding the fish wastage on board, this code proposes to treat wastes in the vessels where that is possible, or to keep them for an ulterior treatment on shore, but never dump them into the sea. These guidelines have been recently assumed by the European Commission (EU, 2002; EU, 2007), which introduces a discard ban, where all finfish and crustaceans caught will have to be landed, including fish above the quota or below minimum market size. Technical solutions to handle these by-catches are to be considered, whether they will be sold through normal market systems, for human consumption, for reduction to fish meal and oil or otherwise (Dumay et al., 2006; Folador et al., 2006; Kristinsson and Rasco, 2000; Bentis et al., 2005). In this framework, considering that all the fish discards must be landed, a preliminary pressing operation may reduce the volume to be stored on board, and thus the refrigeration and space requirements. This is a solution which was already proposed by the Code of Conduct for Responsible Fisheries in order to reduce the volume of by-catches and wastes to be stored on board. As a consequence of pressing operations, two fractions are obtained: a solid cake which is stored on board and can be subsequently reduced to fish meal on shore (Bimbo, 1990; Folador et al., 2006) and a press liquor consisting in an aqueous phase (containing valuable proteins) and an oil phase, as well as a variable amount of fine suspended solids.

In the case of marine materials, pressing can be carried out in continuous mode by screw presses or batchwise, by means of a hydraulic press. Screw presses need a constant supply of byproducts to be treated, they can be used as dewatering pretreatment for fish meal production (Bimbo, 1990; Tiller, 1999), for the preparation of fish laminates (Jeevanandam et al., 2001) and also in fish oil extraction from fatty species such as herring (Aidos et al., 2003). As the raw material is conveyed by one or two parallel screws along a perforated barrel, the volume between the screw flights is gradually reduced, thus increasing the pressure at which the material is subjected and the amount of liquid expressed. The performance of the screw press depends on two main factors: the pressure exerted on the material between the screw flights and the 
rate of revolution of the screws, which is directly related to the pressing time (FAO, 1986).

In a hydraulic press, the raw material is placed in the press chamber where it is compressed by means of a piston actuated by a hydraulic force. This operation involves both compaction of the material and dead-end filtration of the draining liquid through the porous of the raw material until the collecting outlet. The batch operation mode offered by hydraulic presses is preferred when small amounts of raw material are to be processed as would be the case of inshore fishing. Morevorer, on board of a fishing vessel, the supply of raw material (discards and wastes/byproducts from fish processing on board) is not continuous during the day (for example, trawling nets are normally hauled after three hours, three of four times a day). In addition, the cake obtained from the hydraulic press is more compact and presents a lower moisture content, which involves a greater volume reduction. The screw press liquor is highly charged in solid particles, as the degree of tissue disruption is higher due to the development of shearing forces in combination with compressive pressures. Finally, the hydraulic pressing involves lower energetic costs (only those involved in the pumping of the hydraulic fluid into the piston) and it does not need a water supply to facilitate the pressing performance.

It is noticeable the lack of references in literature concerning the hydraulic pressing of seafood species. Among the few works, Chantachum et al. (2000) studied the yield and quality of the fish oil extracted from precooked and non-precooked tuna heads by pressing at 140 ton $/ \mathrm{m}^{2}$ using a hydraulic press. Wu and Chang (1980) employed hydraulic pressing for the recovery of proteins from Antarctic krill, obtaining an optimum yield of $50 \%$ of crude protein by pressing at $2000-2500$ psi. Although the yield was lower than those obtained by extraction with salt or alkali (85\%), the protein recovered was of good nutritional value and functional properties.

The aim of this paper is to optimise the pressing operation parameters, focusing on sardine (Sardina Pilchardus) as model discard. Worldwide, total landings of small pelagics (sardine, mackerel and horse mackerel) are about 4 million tones leading to about 50000 tones of discards (FAO, 2004). Sardine discards are mostly composed of by-catch species, such as anchovy, or small-sized species (European fisheries regulations avoid landing sardines with less than $11 \mathrm{~cm}$ length for the Atlantic Ocean). In some Mediterranean fisheries, sardine discard rate arises to $50 \%$, due to the presence of by-catch species of anchovy. Thus, sardine discards represent an important volume of underutilized biosources whose up-grading should be considered. Pressing must be optimised in order to obtain a good volume reduction in the dewatered cake and a maximal yield of press liquor. Since pressing may be followed by other filtration operations to treat the press liquor, the concentration of insoluble matter in the effluents must be limited, in order to minimize the deposition of suspended particles from the effluent stream on the filtration medium. This constraint implies a multiobjective optimisation problem in which a set of efficient solutions must be found.

\section{Materials and methods}

\subsection{Raw material}

Fresh whole sardine was provided by a local market and directly stored in a refrigerated room at $4{ }^{\circ} \mathrm{C}$. All the pressing tests were carried out in the same day in order to keep the freshness of the raw material. 


\subsection{Pressing operation}

Whole sardine at an initial temperature of $4{ }^{\circ} \mathrm{C}$ was pressed at a room temperature of $10^{\circ} \mathrm{C}$ using a hydraulic press (Tinkturenpressen HP-5M, Fischer-Maschinenfabrik, Neuss, Germany) able to apply pressures up to 370 bar. For each test, $3 \mathrm{Kg}$ of sample were fed into a press basket of $200 \mathrm{~mm}$ diameter and $150 \mathrm{~mm}$ high. The size of the openings located in the base was $1 \mathrm{~mm}$. No heat was applied to the samples, in order to minimize the energetic costs of the process. The pressure reached inside the press chamber was monitored by means of a press transmitter (dTRANS p30, Jumo, Fulda, Germany), attached to a software tool designed to control the process, in terms of compression speed, number of compression steps and time of relaxation between two consecutive compression steps.

\subsection{Input variables}

The raw material was pressed until the target pressure was achieved. This is performed in several stages, which are composed of a compression stage, where the piston descends exerting direct pressure on the material, followed by a relaxation period where the piston stops, helping the liquid to drain. The pressure declines slightly during the relaxation period due to the flux of liquid leaving the basket. An example of this type of operation can be seen in Fig. 1. A target pressure of 300 bar is achieved in 4 stages in a total time of $18.6 \mathrm{~min}$. The increment of pressure performed in each stage is equal for all the stages (75 bar in the example).

With the aim of optimising this operation, four input variables were studied: the final pressure after all the pressing stages $\left(X_{1}\right)$, the compression speed at which the piston descends $\left(X_{2}\right)$, the number of stages involved in the operation $\left(X_{3}\right)$ and the time of relaxation between two consecutive compression stages $\left(X_{4}\right)$.

Figure 1. Evolution of pressure inside the chamber of the hydraulic press.

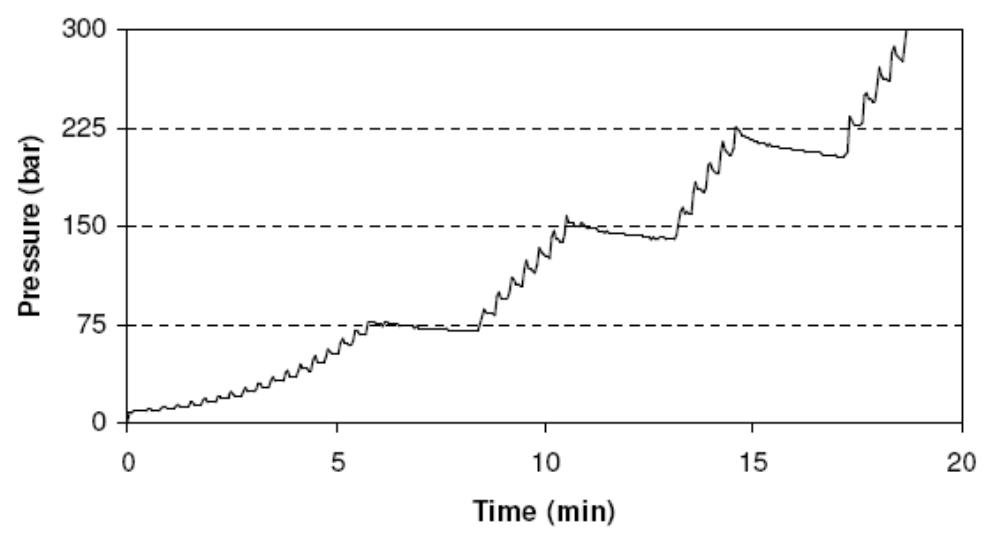

\subsection{Output variables}

Two responses or output variables were measured for each experience: the yield of press liquor $\left(\mathrm{Y}_{1}\right)$ and its content in suspended solids $\left(\mathrm{Y}_{2}\right)$.

The yield of press liquor $\left(\mathrm{Y}_{1}\right)$ was defined as the mass of press liquor collected after pressing, divided by the mass of raw sardine fed into the press. It was measured by weighting all the press liquor collected after all the compression-relaxation stages were accomplished.

The content in suspended solids in the liquor $\left(\mathrm{Y}_{2}\right)$ was defined as the mass of solids in the press liquor divided by the mass of raw sardine fed into the press. Once the press liquor was collected, it was centrifuged at $4000 \mathrm{~g}$ at $4{ }^{\circ} \mathrm{C}$ for 15 minutes (Avanti J-E 
Centrifuge, Beckman Coulter, Fullerton CA, USA) in order to separate it into three phases, an oily phase, an aqueous phase containing most of the soluble compounds and a solid residue. The wet weight of this solid phase was measured, because this value will be more useful with regard to an ulterior filtration operation.

\subsection{Experimental design}

The compression of the raw material in the hydraulic press can be assumed to be analogous to the consolidation of a saturated soil, and thus obey the theory by Terzaghi (1943). The term consolidation in soils mechanics refers to volume change due entirely to the expulsion of pore fluids under pressure (Bargale et al., 2000). Models based on Terzaghi's theory have been traditionally used to predict the cake consolidation and the flux of oil expressed from oilseeds by uniaxial compression (Venter et al., 2007). In our case, the cake cannot be considered as homogeneous as the raw material is introduced inside the press basket without being grinded previously, the press liquor is a mixture of different liquid phases (water, oil, blood) with different rheological properties, and no data are available concerning the cake consolidation, in terms of porosity, permeability or mechanical behavior of the cake. For this reason, the effects of the 4 independent variables on the liquor yield and the fraction of suspended solids were investigated statically by response surface methodology (Montgomery and Myers, 1995; Erikson et al., 2000). A rotable central composite design with 5 levels was chosen for this purpose, as shown in Table 1.

The Statgraphics software (version 5.1) was used to generate the experimental design, the statistical analysis and the regression model. The response functions were related to the input variables by a second degree polynomial as follows:

$$
\begin{aligned}
& \mathrm{Y}_{1}=\mathrm{b}_{0}+\sum_{\mathrm{i}=1}^{4} \mathrm{~b}_{\mathrm{i}} \mathrm{X}_{\mathrm{i}}+\sum_{\mathrm{i}=1}^{4} \mathrm{~b}_{\mathrm{ii}} \mathrm{X}_{\mathrm{i}}^{2}+\sum_{\mathrm{i}<\mathrm{j}}^{4} \mathrm{~b}_{\mathrm{ij}} \mathrm{X}_{\mathrm{i}} \mathrm{X}_{\mathrm{j}} \\
& -\ln \left(\mathrm{Y}_{2}\right)=\mathrm{b}_{0}+\sum_{\mathrm{i}=1}^{4} \mathrm{~b}_{\mathrm{i}} \mathrm{X}_{\mathrm{i}}+\sum_{\mathrm{i}=1}^{4} \mathrm{~b}_{\mathrm{ii}} \mathrm{X}_{\mathrm{i}}^{2}+\sum_{\mathrm{i}<\mathrm{j}}^{4} \mathrm{~b}_{\mathrm{ij}} \mathrm{X}_{\mathrm{i}} \mathrm{X}_{\mathrm{j}}
\end{aligned}
$$

where the coefficients $b_{i}$ and $b_{i i}$ are related to the linear and quadratic effects, respectively, of each input factor on the response and the cross-product coefficients $b_{i j}$ represent the interactions between two input variables. The modified variable $-\ln \left(\mathrm{Y}_{2}\right)$ was chosen (instead of the original $\mathrm{Y}_{2}$ ) in order to obtain a better correlation when fitting the data to the regression model.

The analysis of variance (ANOVA) tables were generated. The significance of all terms in the polynomial was judged statistically by computing the $p$-value. The regression coefficients were then used to generate contour maps and optimise each single response. 
Table 1. Levels of the input variables

\begin{tabular}{ccccc}
\hline \multirow{2}{*}{ Level } & Pressure (bar) & Speed (cm/min) & Steps (-) & Time (s) \\
& $\mathrm{X}_{1}$ & $\mathrm{X}_{2}$ & $\mathrm{X}_{3}$ & $\mathrm{X}_{4}$ \\
\hline-2 & 50 & 0.935 & 1 & 100 \\
-1 & 125 & 1.485 & 2 & 150 \\
0 & 200 & 2.035 & 3 & 200 \\
+1 & 275 & 2.585 & 4 & 250 \\
+2 & 350 & 3.135 & 5 & 300 \\
\hline
\end{tabular}

\subsection{Multiobjective optimisation}

A problem of multiobjective optimisation arises when several objectives (possibly conflicting) must be satisfied. The multiobjective optimisation problem can be defined (Osyczka, 1985) as the problem of finding a vector of decision variables which satisfies constraints and optimises a vector function whose elements represent the objectives. The solution vector should give values of all the objective functions acceptable to the decision maker. If any of the components of the objective function are competing, there is no unique solution to this problem. Then the concept of Pareto Front must be used in order to find and adequate solution. The Pareto Front is defined as the set of noninferior solutions which satisfies all the constraints of the multiobjective optimisation problem. A noninferior solution is one in which an improvement in one objective requires a degradation of another (Kim and Weck, 2005; Halsall-Whitney and Thibault, 2006).

The techniques to generate the Pareto Front are wide and varied. The $\varepsilon$-constraint method was chosen for this purpose in this work. This involves optimising a primary objective and expressing the other objectives in the form of inequality constraints.

On the other hand, the integer nature of one of the input variables $\left(X_{3}\right.$, number of compression steps) involves the employment of appropriate algorithms to solve each optimisation problem. In this work, the Branch and Bound (B\&B) method was used (Pibouleau et al., 2000), which is based on the following two basic principles: (i) a partitioning method for the independent variables to divide up all the possible feasible solutions into subsets; (ii) a search for the optimum solution in the most promising subsets. The Solver Tool, included in the MS Excel software was chosen for this purpose as it incorporates $B \& B$ algorithms for mixed integer nonlinear optimisation.

\section{Results and discussion}

\subsection{Regression model and analysis of variance}

Hydraulic pressing has been employed to obtain a partially dewatered cake and a press liquor. This is a solution which was already suggested by the European Code of sustainable and responsible fisheries practices (EU, 2004) in order to reduce the volume of wastes to be stored on board and has been successfully employed to recover fish oil (Chantachum et al., 2000) or proteins (Wu and Chang, 1980) from seafood species. Unlike traditional processes, the raw material has not been submitted 
to a heat pre-treatment in order to avoid protein denaturation in cake and press liquor, as well as to minimise energy consumption.

As a consequence of pressing a partially dewatered cake was obtained. For each experiment the reduction in volume of cake was measured. An average reduction of 40-45 \% was measured for all the samples, showing no significant variability or correlation with experimental factors. Considering that an average yield of liquor of 10 $\%$ (mass of water per mass of whole sardine) is obtained after pressing with a volume reduction in the cake of $40 \%$, the storage density (mass stored per pallet) is increased in a $50 \%$. For a fixed storage capacity and pallets layout, this results in a decrease of the store area of about $33 \%$. This results in less construction costs and refrigeration loads for insulation and air changes, which depend directly on the cold store dimensions.

Table 2 shows the experimentally measured and the regression model predicted values of the response variables. Employing a complete central composite design, with four independent variables and three central points, a total of 27 experiments were conducted. All these experiments led to a volume reduction of $40-45 \%$ in the final cake, related to the initial volume of the raw material. In general, a lower moisture content in cake facilitates the ulterior waste handling and processing (García et al., 2005). The correlation between experimental and predicted values was found to be good, with the coefficients of correlation $r=0.984$ for $Y_{1}$ and $r=0.924$ for $-\ln \left(Y_{2}\right)$.

The experimental data were fitted to a complete quadratic model and the regression coefficients were calculated, as well as their statistical significance by means of an analysis of variance, as shown in Table 3. Similar statistical procedures have already been employed to optimise fish oil quality from herring byproducts using a three-phase decanter (Aidos et al., 2003) or to study the perfomance of several enzymes on the hydrolysis of fish wastes from several sources such as sardine (Dumay, 2006) or Atlantic salmon (Liaset et al., 2002). The statistical analysis states that the four independent variables are significant on the liquor yield, as well as the quadratic effects of pressure, compression speed and number of compression stages. The effect of interactions on the liquor yield was not significant as their associated probabilities were higher than 0.05. Concerning the second response, it depends mainly on the linear and quadratic effect of pressure, as well as the linear effect of the speed of compression. The number of stages is significant only in its quadratic effect and no effect containing the time of relaxation was found to be significant. 
Table 2. Rotable central composite design and comparison between experimental vs predicted values for the response variables

\begin{tabular}{|c|c|c|c|c|c|c|c|c|}
\hline $\begin{array}{c}\text { Exp } \\
\# \\
\end{array}$ & $\begin{array}{c}\mathrm{X}_{1} \\
\text { (bar) }\end{array}$ & $\begin{array}{c}\mathrm{X}_{2} \\
(\mathrm{~cm} / \mathrm{min})\end{array}$ & $\begin{array}{l}\mathrm{X}_{3} \\
(-) \\
\end{array}$ & $\begin{array}{l}X_{4} \\
(s)\end{array}$ & $\begin{array}{c}\mathrm{Y}_{1} \\
\text { Exp. }\end{array}$ & $\begin{array}{c}\mathrm{Y}_{1} \\
\text { Pred. }\end{array}$ & $\begin{array}{c}-\ln \left(\mathrm{Y}_{2}\right) \\
\text { Exp. }\end{array}$ & $\begin{array}{c}-\ln \left(\mathrm{Y}_{2}\right) \\
\text { Pred. }\end{array}$ \\
\hline 1 & 125 & 1.485 & 2 & 150 & 0.058 & 0.063 & 4.978 & 4.910 \\
\hline 2 & 275 & 1.485 & 2 & 150 & 0.103 & 0.106 & 4.091 & 4.060 \\
\hline 3 & 125 & 2.585 & 2 & 150 & 0.058 & 0.057 & 4.870 & 4.841 \\
\hline 4 & 275 & 2.585 & 2 & 150 & 0.093 & 0.092 & 4.208 & 4.268 \\
\hline 5 & 125 & 1.485 & 4 & 150 & 0.074 & 0.075 & 4.723 & 4.788 \\
\hline 6 & 275 & 1.485 & 4 & 150 & 0.113 & 0.118 & 4.335 & 4.160 \\
\hline 7 & 125 & 2.585 & 4 & 150 & 0.071 & 0.075 & 4.873 & 4.809 \\
\hline 8 & 275 & 2.585 & 4 & 150 & 0.106 & 0.108 & 4.681 & 4.458 \\
\hline 9 & 125 & 1.485 & 2 & 250 & 0.067 & 0.070 & 4.673 & 4.848 \\
\hline 10 & 275 & 1.485 & 2 & 250 & 0.108 & 0.108 & 4.110 & 4.008 \\
\hline 11 & 125 & 2.585 & 2 & 250 & 0.062 & 0.061 & 5.024 & 5.033 \\
\hline 12 & 275 & 2.585 & 2 & 250 & 0.086 & 0.090 & 4.582 & 4.470 \\
\hline 13 & 125 & 1.485 & 4 & 250 & 0.085 & 0.090 & 4.697 & 4.471 \\
\hline 14 & 275 & 1.485 & 4 & 250 & 0.121 & 0.126 & 3.872 & 3.853 \\
\hline 15 & 125 & 2.585 & 4 & 250 & 0.084 & 0.086 & 4.763 & 4.747 \\
\hline 16 & 275 & 2.585 & 4 & 250 & 0.114 & 0.113 & 4.504 & 4.406 \\
\hline 17 & 50 & 2.035 & 3 & 200 & 0.059 & 0.054 & 5.193 & 5.163 \\
\hline 18 & 350 & 2.035 & 3 & 200 & 0.129 & 0.125 & 3.728 & 3.972 \\
\hline 19 & 200 & 0.935 & 3 & 200 & 0.103 & 0.094 & 4.203 & 4.330 \\
\hline 20 & 200 & $2.585^{\mathrm{a}}$ & 3 & 200 & 0.094 & 0.094 & 4.032 & 4.377 \\
\hline 21 & 200 & 2.035 & 1 & 200 & 0.073 & 0.072 & 4.718 & 4.660 \\
\hline 22 & 200 & 2.035 & 5 & 200 & 0.116 & 0.108 & 4.201 & 4.473 \\
\hline 23 & 200 & 2.035 & 3 & 100 & 0.093 & 0.089 & 4.258 & 4.384 \\
\hline 24 & 200 & 2.035 & 3 & 300 & 0.106 & 0.101 & 4.182 & 4.269 \\
\hline 25 & 200 & 2.035 & 3 & 200 & 0.101 & 0.104 & 4.259 & 4.150 \\
\hline 26 & 200 & 2.035 & 3 & 200 & 0.102 & 0.104 & 4.284 & 4.150 \\
\hline 27 & 200 & 2.035 & 3 & 200 & 0.108 & 0.104 & 4.168 & 4.150 \\
\hline
\end{tabular}

a $2.585 \mathrm{~cm} / \mathrm{min}($ level +1$)$ were applied in this experiment instead of $3.135($ level +2$)$ due to technical limitations. 
Table 3. Regression coefficients and p-values for the response variables

\begin{tabular}{lcccc}
\hline \multirow{2}{*}{ Term } & \multicolumn{2}{c}{$\mathrm{Y}_{1}$} & \multicolumn{2}{c}{$-\ln \left(\mathrm{Y}_{2}\right)$} \\
\cline { 2 - 5 } & Coefficient & $\mathrm{p}$-value & Coefficient & $\mathrm{p}$-value \\
\hline $\mathrm{b}_{0}$ & -0.1365 & 0.0000 & 10.1591 & 0.0000 \\
$\mathrm{~b}_{1}$ & 0.0007 & 0.0000 & -0.0172 & 0.0000 \\
$\mathrm{~b}_{2}$ & 0.0645 & 0.0047 & -2.1208 & 0.0298 \\
$\mathrm{~b}_{3}$ & 0.0184 & 0.0000 & -0.6477 & 0.3020 \\
$\mathrm{~b}_{4}$ & 0.0004 & 0.0192 & -0.0086 & 0.5219 \\
$\mathrm{~b}_{11}$ & $-6.29 \cdot 10^{-7}$ & 0.0122 & $1.85 \cdot 10^{-5}$ & 0.0361 \\
$\mathrm{~b}_{12}$ & $-5.45 \cdot 10^{-5}$ & 0.1407 & 0.0017 & 0.2154 \\
$\mathrm{~b}_{13}$ & $-4.33 \cdot 10^{-5}$ & 0.8236 & 0.0007 & 0.3148 \\
$\mathrm{~b}_{14}$ & $-3.90 \cdot 10^{-7}$ & 0.3255 & $6.44 \cdot 10^{-7}$ & 0.9644 \\
$\mathrm{~b}_{22}$ & -0.0152 & 0.0113 & 0.3486 & 0.0901 \\
$\mathrm{~b}_{23}$ & 0.0021 & 0.4262 & 0.0411 & 0.6770 \\
$\mathrm{~b}_{24}$ & $-3.23 \cdot 10^{-5}$ & 0.5455 & 0.0023 & 0.2533 \\
$\mathrm{~b}_{33}$ & -0.0034 & 0.0148 & 0.1039 & 0.0366 \\
$\mathrm{~b}_{34}$ & $3.78 \cdot 10^{-5}$ & 0.2105 & -0.0013 & 0.2530 \\
$\mathrm{~b}_{44}$ & $-8.44 \cdot 10^{-7}$ & 0.1016 & $1.76 \cdot 10^{-5}$ & 0.3390 \\
\hline
\end{tabular}

\subsection{Optimisation of response variables}

With the help of the regression model, the combination of factors which determine a maximal liquor yield (13.45 \%) can be obtained by means of branch and bound at 350 bar of final pressure, $1.540 \mathrm{~cm} / \mathrm{min}$ of compression speed, 4 compression stages and a time of relaxation of $242 \mathrm{~s}$. Pressure exerts a positive effect on the liquor yield, so working at higher pressures should report an increase in the quantity of press liquor collected. The fact of employing 5 or more compression stages does not improve the liquor yield, as well as relaxation times longer than 240 seconds. The compression speed has a significant quadratic effect $(p=0.0113)$ which determines an optimal value placed in the range of experimental data.

Concerning the fraction of suspended solids, the maximum value of the variable $\ln \left(Y_{2}\right)$, and therefore the minimal value of $Y_{2}(0.002)$ is reached at 66 bar, a compression speed of $2.585 \mathrm{~cm} / \mathrm{min}, 1$ compression stage, and the maximal time of relaxation allowed (300 s). The variable which mostly influenced the fraction of suspended solids was the pressure, with both linear and quadratic effects of significance. This fact implied that the optimum was found inside the range of experimental data (50 - 350 bar). Its effect was positive on the content of suspended solids, as an increase in the final pressure determines a more charged press liquor. On the other hand, a higher compression speed leads to a lower concentration of suspended solids in the press liquor, with a strong linear dependence and no quadratic or interaction effects of significance, so its optimal value coincided with its upper bound.

These results indicate that the effect of pressure on the optimisation of both responses is opposite. While a higher pressure leads to a better efficiency of the pressing operation, the degree of damage on the raw material is higher, and as a consequence the press liquor is more charged in suspended solids. A higher compression speed 
implies shorter compression stages, and thus a lower compression work, which results in a lower liquor yield but also less issue disruption in the raw material, obtaining a press liquor with lower organic load.

The application of several compression stages permits to increase the efficiency of the pressing operation even if high compression speeds are employed, so its effect on liquor yield should be positive. As we increase the number of compression stages, the flux of liquid collected in each one is lower and more charged in suspended solids, as the raw material becomes more dewatered and damaged. This could explain the fact that the optimal yield was achieved at four pressing stages, since applying another compression stage would not improve it significantly and also the minimum of suspended solids, found when only one compression stage was undertaken.

The relaxation time exerts a positive effect on the accomplishment of both objectives. An increase of this variable gives rise not only to a higher quantity of press liquor, but also to a lower content of suspended solids in it. This might be due to the blocking of the press outlet by the particles of suspended solids, so only liquid can leave the press chamber.

Fig. 2 shows the contour plots for both responses, with pressure and number of compression stages set at their optimal values. It can be noticed that optimal values are placed inside the range of factors (Fig. 2a) and in the upper bound (Fig. 2b). This suggests that better results concerning the content of suspended solids in the press liquor could be achieved by working at higher times of relaxation and speeds of compression, but this would result in lower yields. 
Figure 2. Contour plots for the response variables, (a) $Y_{1}$ at 350 bar and 4 pressing stages, (b) $-\ln \left(Y_{2}\right)$ at 66 bar and 1 compression stage

(a)

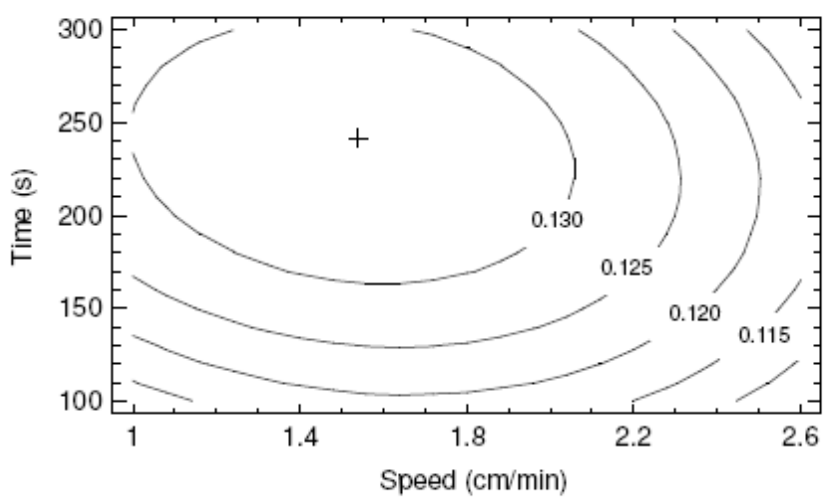

(b)

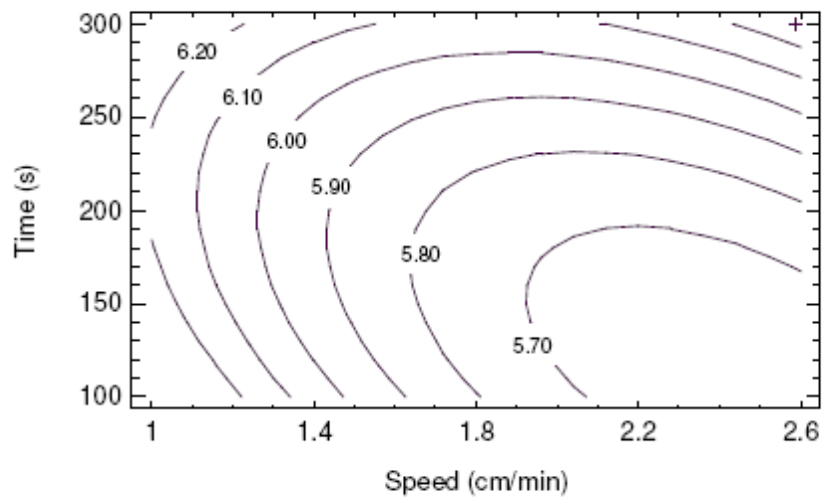

\subsection{Multiobjective optimisation}

The conflict between the two responses suggested employing a multiobjective optimisation technique. A Pareto Front was generated in order to find a set of solutions which satisfied in an adequate degree both objectives. The $\varepsilon$-constraint method was chosen for this purpose. The optimisation problem consisted in estimating the maximum yield that could be achieved without exceeding a fixed fraction of suspended solids in the press liquor. This fraction of suspended solids was calculated as the ratio between $Y_{2}$ and $Y_{1}$. The solution should be obtained by a combination of factors inside the ranges of the independent variables or decision space. This is a multiobjective optimisation problem with constraints which could be formulated as follows:

Maximise: $Y_{1}$

Subjected to: $Y_{2} / Y_{1}<\varepsilon$

The results generated after the optimisation (Table 4) show the maximum liquor yields that could be obtained by allowing a set of fractions of suspended solids from 0.05 to 0.15. As expected, the higher the limitation in suspended solids, the higher the yield obtained. Liquor yield ranges from 0.1021 to 0.1342 when the fraction of suspended solids allowed increases from 0.05 to 0.15 . This latter value is close to the unrestricted 
maximum yield shown above (0.1345). All this set of non-inferior solutions corresponds to the maximum pressure allowed (350 bar), which optimises the yield of press liquor, and different combinations of the rest of decision variables. Up to a fraction of suspended solids of 0.14 , the optimum number of compression stages is 5 . This value changes to 4 afterwards. This may be explained by the blocking of the filter basket and press outlet by the particles of suspended solids, which avoids collecting more liquid when a next compression step is applied. While the optimum number of steps is 5 , the optimum relaxation time increases from 100 to 256 s. Similarly, when 4 steps are optimum, optimum time increases from 213 to $230 \mathrm{~s}$.

The selection of a single optimal solution inside the Pareto Front will depend on the technical requirements of the subsequent operations to treat the effluents, specially the maximal content in suspended solids able to be removed by the micro and ultrafiltration devices.

\section{Table 4. Set of optimal solutions (Pareto front) for the multiobjective} optimisation problem.

\begin{tabular}{cccccc}
\hline $\begin{array}{c}\text { Upper } \\
\text { bound }\end{array}$ & $\begin{array}{c}\text { Optimum } \\
\mathrm{X}_{1}(\mathrm{bar})\end{array}$ & $\begin{array}{c}\text { Optimum } \\
\mathrm{X}_{2}(\mathrm{~cm} / \mathrm{min})\end{array}$ & $\begin{array}{c}\text { Optimum } \\
\mathrm{X}_{3}(-)\end{array}$ & $\begin{array}{c}\text { Optimum } \\
\mathrm{X}_{4}(\mathrm{~s})\end{array}$ & $\begin{array}{c}\text { Maximum } \\
\mathrm{Y}_{1}(-)\end{array}$ \\
\hline 0.05 & 350 & 2.585 & 5 & 100 & 0.1021 \\
0.06 & 350 & 2.585 & 5 & 177 & 0.1149 \\
0.07 & 350 & 2.422 & 5 & 209 & 0.1217 \\
0.08 & 350 & 2.200 & 5 & 209 & 0.1263 \\
0.09 & 350 & 2.003 & 5 & 218 & 0.1297 \\
0.10 & 350 & 1.830 & 5 & 230 & 0.1318 \\
0.11 & 350 & 1.674 & 5 & 245 & 0.1330 \\
0.12 & 350 & 1.575 & 5 & 256 & 0.1332 \\
0.13 & 350 & 1.575 & 5 & 256 & 0.1332 \\
0.14 & 350 & 1.704 & 4 & 213 & 0.1335 \\
0.15 & 350 & 1.559 & 4 & 230 & 0.1342 \\
\hline
\end{tabular}

\section{Conclusion}

Whole sardine was pressed using a hydraulic press, working at different combinations of pressure, speed of compression, number of compression steps and time of relaxation between them. As a result of this, a partially dewatered cake is obtained, with a reduction of volume of $40-45 \%$ related to the initial raw material. This implies less refrigeration and space requirements, related to the storage of the whole fish. The yield of press liquor and its content in suspended solids were measured and fitted to a second-order model with high correlation coefficients (0.982 and 0.924, respectively). Once the polynomial models were obtained, the optimisation of both responses was carried out. The surface response graphs show that a maximum yield of $13.45 \% \mathrm{w} / \mathrm{w}$ (related to the mass of sardine fed into the press) was obtained at the pressing 
conditions of pressure of 350 bar, compression speed of $1.54 \mathrm{~cm} / \mathrm{min}, 5$ compression steps and maximal time of relaxation. The minimal content in suspended solids was found to be $0.2 \% \mathrm{w} / \mathrm{w}$ at a pressure of $66 \mathrm{bar}$, compression speed of $2.585 \mathrm{~cm} / \mathrm{min}, 1$ compression step and maximum time of relaxation. The opposite behavior of the experimental factors towards the accomplishment of the optimisation objectives obliges to find a compromise solution by using multiobjective optimisation techniques. The $\varepsilon-$ constrain method was chosen for this purpose, generating a set of optimal solutions (Pareto Front) which assures a maximal yield with a limited content in suspended solids in the press liquor. The ulterior treatment of the effluents of the pressing operation will determine the selection of a single solution inside the Pareto Front, in terms of minimum flux of liquid required or maximum concentration of suspended solids allowed.

\section{References}

Aidos, I., Kreb, N., Boonman, M., Luten, J.B., Boom, R.M., van der Padt, A., 2003. Influence of Production Process Parameters on Fish Oil Quality in a Pilot Plant. Journal of Food Science 68, 581-587.

Bargale, P.C., Wulfsohn, D., Irudayaraj, J., Ford, R.J., Sosulski, F.W., 2000. Prediction of Oil Expression by Uniaxial Compression using Time-varying Oilseed Properties. Journal of Agricultural Engineering Research 77, 171-181.

Bentis, C.A., Zotos, A., Petridis, D., 2005. Production of fish-protein products (surimi) from small pelagic fish (Sardinops pilchardusts), underutilized by the industry. Journal of Food Engineering 68, 303-308.

Bimbo, A.P., 1990. Production of fish oil. In: Stansby, M.E. (Ed.), Fish oils in nutrition, 141-180. Reinhold Publishing, New York.

Blanco, M., Sotelo, C.G., Chapela, M.J., Perez-Martin, R.I., 2007. Towards sustainable and efficient use of fishery resources: present and future trends. Trends in Food Science and Technology 18, 29-36.

Chantachum, S., Benjakul, S., Sriwirat, N., 2000. Separation and quality of fish oil from precooked and non-precooked tuna heads. Food Chemistry 69, 289-294.

Dumay, J., 2006. Extraction de lipides en voie aqueuse par bioréacteur enzymatique combiné à l'ultrafiltration: application à la valorisation de co-produits de poisson (Sardina pilchardus). Doctoral Thesis, Institute Français de Recherche pour l'Explotation de la Mer.

Dumay, J., Donnay-Moreno, C., Barnathan, G., Jaouen, P., Bergé, J.P., 2006. Improvement of lipid and phospholipid recoveries from sardine (Sardina pilchardus) viscera using industrial proteases. Process Biochemistry 41, 2327-2332.

Erikson, L., Johasson, E., Kettaneh-Wold, N., Wikström, C., Wold, S., 2000. Design of experiments: Principles and Applications. Umetrics Academy, Sweeden.

EU, 2002. Community Action Plan to reduce discards of fish. European Commission communication COM(2002) 656.

EU, 2004. European Code of sustainable and responsible fisheries practices. European Commission Publication.

EU, 2007. A policy to reduce unwanted by-catches and eliminate discards in European fisheries. Commission communication COM(2007) 136.

FAO, 1986. The production of fish meal and oil. FAO Fisheries Technical Paper 142.

FAO, 2004. Review of the state of world's marine fishery resources. FAO Fisheries Technical Paper 457.

Folador, J.F., Karr-Lilienthal, L.K., Parsons, C.M., Bauer, L.L., Utterback, P.L., Schasteen, C.S., Bechtel, P.J., Fahey, G.C., 2006. Fish meals, fish components and fish protein hydrolysates as potential ingredients in pet foods. Journal of Animal Science 84, 2752-2765. 
García, A.J., Esteban, M.B., Márquez, M.C., Ramos, P., 2005. Biodegradable municipal solid waste: characterization and potential use as animal feedstuffs. Waste Management 25, 780-787.

Halsall-Whitney, H., Thibault, J., 2006. Multi-objetive optimization for chemical processes and controller design: approximating and classifying the Pareto Domain. Computers and Chemical Engineering 30, 1155-1168.

Jeevanandam, K., Venugopal, V., Doke, S.N., Rao, B.Y.K., Bongirwar, D.R., 2001. Preparation and storage characteristics of ribbon fish laminates. Journal of Aquatic Food Product Technology 10, 77-86.

Kim, I.Y., de Weck, O.L., 2005. Adaptive weighted-sum method for bi-objetive optization: Pareto front generation. Structural and Multidisciplinary Optimization 31, 105-116.

Kristinsson, H.G., Rasco, B.A., 2000. Fish Protein Hydrolysates: Production, Biochemical, and Functional Properties. Critical Reviews in Food Science and Nutrition 40, 43-81.

Liaset, B., Nortvedt, R., Lied, E., Espe, M., 2002. Studies on the nitrogen recovery in enzymic hydrolysis of Atlantic salmon (Salmo salar, L.) frames by Protamex ${ }^{\mathrm{TM}}$ protease. Process Biochemistry 37, 1263-1269.

Montgomery, D.C., Myers, R.H., 1995. Response Surface Methodology: Process and product optimisation using designed experiments. Wiley-Interscience, New York.

Osyczka, 1985. Multicriteria optimization for engineering design. In: Gero, J.S., Design Optimization, 193-227, Academic Press, New York.

Pibouleau, L., Floquet, P., Domenech, S., 2000. Fuzziness and branch and bound procedures: Applications to separation sequencing. Fuzzy Sets and Systems 109, 111-127.

Tiller, C.H., 1999. Method for producing fish meal. United States Patent 5972403.

Terzaghi K., 1943. Theoretical Soil Mechanics. Wiley, New York.

Venter, M.J., Kuipers, N.J.M., de Haan, A.B., 2007. Modelling and experimental evaluation of high-pressure expression of cocoa nibs, Journal of Food Engineering 80, 1157-1170.

Wu, M.C., Chang, W.H., 1980. A study on the separation and recovery of Antarctic Krill protein. Council for Agricultural Planning \& Development, Taipei (Taiwan). 